\title{
"EFFECT ON HEMODYNAMIC RESPONSE TO LARYNGOSCOPY AND TRACHIAL INTUBATION AND THEIR ATTENUATION BY BOLUS ADMINISTRATION OF DEXMEDETOMIDINE"
}

\section{Dr.Rituraj Saini* \\ Dr.Urmila Keshari}

Junior Resident, Dept.Of Anaesthesiology \& Critical Care, Gandhi Medical College, Bhopal. *Corrresponding Author

Professor,Dept.Of Anaesthesiology \& Critical Care, Gandhi Medical College, Bhopal.

ABSTRACT Background and Aims- Laryngoscopic and endotracheal intubation are noxious stimuli causes tachycardia, arrhythmias and hypertension. The aim of this study was to compare dexmedetomidine with placebo to attenuate stress response during laryngoscopy and endotracheal intubation.Methods-It was a randomised, doubleblind placebo-controlled study. After Institutional Ethical Committee clearance, 60 patients of ASA $1 \& 2$ were enrolled and divided into 30 each. Group NS received normal saline and Group D received injection dexmedetomidine $1 \mathrm{~g} / \mathrm{kgas}$ infusion over $10 \mathrm{~min}$. The general anaesthesia technique was standardised for both groups. The primary outcome measures were haemodynamic response at 1, 2,5 and 10 min after intubation. The secondary outcome measures were to note down any adverse effects associated with drugs. The statistical package used was SPSS version 15.Results- There was a statistically significant difference $(P<0.05$ ) between Group D and Group NS in heart rate, systolic, diastolic and mean arterial pressures after tracheal intubation with dexmedetomidine. Sedation scores were more with dexmedetomidine. None of the patients had any adverse effects. Conclusion-Dexmedetomidine $1 \mu \mathrm{g} / \mathrm{kg}$ as premedication can be used safely and effectively to attenuate hemodynamic response to laryngoscopy and endotracheal intubation.

KEYWORDS : Dexmedetomidine, endotracheal intubation.

\section{INTRODUCTION}

Direct laryngoscopy and intubation are noxious stimuli and associated with transient and variable hemodynamic changes. This reflex sympathetic discharge is caused by stimulation of laryngopharynx, and trachea, which are innervated by parasympathetic innervations via vagus and glossopharyngeal nerves and sympathetic via superior cervical ganglion. These pressure response changes depend on premedication, force and duration of laryngoscopy and intubation, depth of anaesthesia and use of any drugs or methods. These consequences of laryngoscopy and intubation usually not hazardous to normal healthy, ASA I and II patients but may precipitate ischemia, arrhythmias, CV stroke, pulmonary oedema, increase intracranial pressure in poor cardiac compliance patients.

Premedication is one of the most valuable element for anaesthesia. Good premedication provide pleasant preoperative psychological conditions, relives anxiety and emesis, produce sedation, hypnosis and analgesia, antisialagogue action, sympatholysis. All these play beneficial role to achieve depth of anaesthesia and provide excellent condition for direct laryngoscopy and intubation.

Till date, variety of agents and drugs have been tried to attenuate stress response, such as opioids, vasodilators, beta blockers, Ca+2 channel blockers, IV lignocaine, topical sprays, volatile agents but no one proved as ideal.

Dexmedetomidine, highly selective and potent 2 adrenergic agonist, has sedative, hypnotic, anxiolytic, analgesic, sympatholytic properties and promotes cardiac, respiratory and neurological stability. In addition, it decreases perioperative catecholamine release.

So, we designed this study to evaluate efficacy and use properties of IV Dexmedetomidine $1 \mu \mathrm{g} / \mathrm{kg}$ as pre-medication in surgeries under general anaesthesia to attenuate hemodynamic responses to laryngoscopy and endotracheal intubation.

\section{MATERIAL AND METHODS}

A randomized, prospective comparative study was carried out at Gandhi medical college and hospital, Bhopal .A written informed anaesthesia consent was obtained and explaining regarding drug and procedure in details to patients of ASA I, II of elective surgeries under general anaesthesia were selected. They were divided in to two groups. Patients in group $\mathrm{NS}(\mathrm{n}=30)$ received $10 \mathrm{ml}$ of normal saline over 10 minutes while in group $D(n=30)$ received IV Dexmedetomidine $1 \mu \mathrm{g} / \mathrm{kg}$ diluted in $10 \mathrm{ml}$ normal saline administered over 10 minutes.

Inclusion criteria were patients with mallampatti grade I, age group 18-60 Years and elective surgeries.

Exclusion criterias were patients with difficult airway, obesity, age $<18$ and $>60$ years, emergency, history of allergy to any drugs, pregnancy and systemic diseases. If laryngoscopy and intubation period exceeds more than 15 seconds, patients were excluded from study.

Detailed preanaesthetic checkup, airway assessment and all necessary investigations were carried out a day before surgery. Patients were kept nil by mouth for 6 hours before surgery. Heart rate, Blood pressure (SBP, DBP and MAP), SpO2, respiratory rate was noted. I.V. line secured with $18 \mathrm{G}$ cannula and inj. RL was started. At operative room, HR (ECG), SBP, DBP and MAP recorded and referred as baseline. Patients were premedicated with IV Glycopyrrolate $0.2 \mathrm{mg}$ and IVOndansetron $4 \mathrm{mg}$. After 10 minutes, Study drug (Dexmedetomidinevs Normal saline) was administered. Heart rate, blood pressure (SBP, DBP, MAP) observed 10 minutes interval after study drug administration. Patients were preoxygenated for 3 minutes with $100 \%$ oxygen. Induction was done with injection Propofol in $2 \mathrm{mg} / \mathrm{kg}$ IV. Endotracheal intubation was facilitated with inj. Succinylcholine $2 \mathrm{mg} / \mathrm{kg}$. Laryngoscopy performed with appropriate size of Machintosh blade, lasting not more than 15 seconds and intubation was performed with endotracheal tube.

Hemodynamic parameters in terms of Heart rate, systolic and diastolic blood pressure, mean arterial pressure observed and recorded at $1 \mathrm{~min}, 2 \mathrm{~min}, 5 \mathrm{~min}$ and 10 minutes interval after laryngoscopy and intubation, referred as T1, T2, T5 and T10. Anaesthesia was maintained on $50 \%$ O2, $50 \%$ N2O, $1 \%$ Sevoflurane and injection Atracurium . $1 \mathrm{mg} / \mathrm{kg}$ immediate after intubation.

No any surgical or other procedure allowed till 10 minutes of 
intubation. We had decided to end study after 10 minutes of intubation with administration of inj. Fentanyl $2 \mu \mathrm{g} / \mathrm{kg}$ as analgesic. We also observed and assessed any complication or side effects like hypotension (a $20 \%$ decrease from baseline value), bradycardia (HR $<50$ beats/min), hypoxemia $\left(\mathrm{SpO}_{2}<90 \%\right)$,Tachycardia ( $>25 \%$ of baseline), arrhythmias, bronchospasm or nausea vomiting any other in relation to drug or procedure.

At the end of surgery, the quality of anaesthesia was assessed according to a numeric scale.

$4=$ excellent: no complaint from patient,

3 = good: Minor complaint with no need for supplemental analgesia,

2 =moderate: Complaint which required supplemental analgesics,

$\mathrm{l}=$ unsuccessful: Patient was given general anaesthesia.

The data were analyzed by Student's $t$-test and Chi-square test. $P$ value $<0.05$ was considered statistically significant.

\section{Statistical Analysis}

It is performed using "unpaired student t-test". p value was calculated using software. $p$ value $<0.01$ indicates highly significant, $p<0.05$ suggests significant and $p>0.05$ means no significant difference between two groups.

\section{RESULTS}

As shown in Table 1, Mean Age, Sex, and weightDemographic data were comparable in both groups.

Table: 1demographic Data.

\begin{tabular}{|l|l|l|}
\hline & Group NS & Group D \\
\hline Age (years) & $33.21 \pm 7.28$ & $32.52 \pm 5.85$ \\
\hline Gender (M:F) & $18: 12$ & $17: 13$ \\
\hline Weight (kg) & $55.34 \pm 7.54$ & $57.12 \pm 6.12$ \\
\hline
\end{tabular}

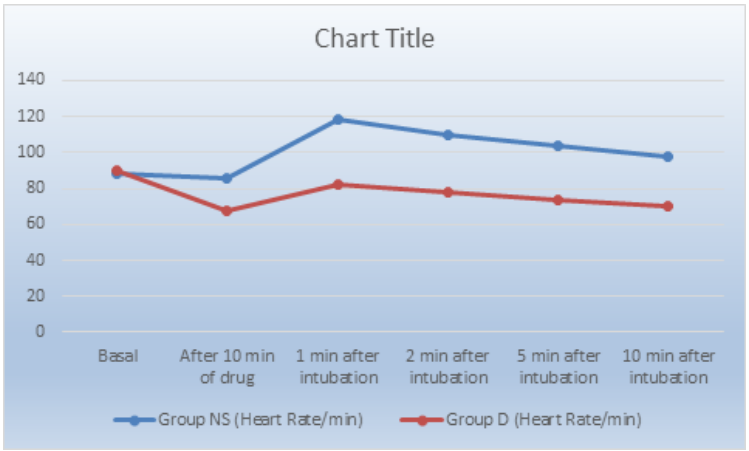

Figure 1: Mean Heart Rate Changes At Different Time Intervals Compared To Baseline.

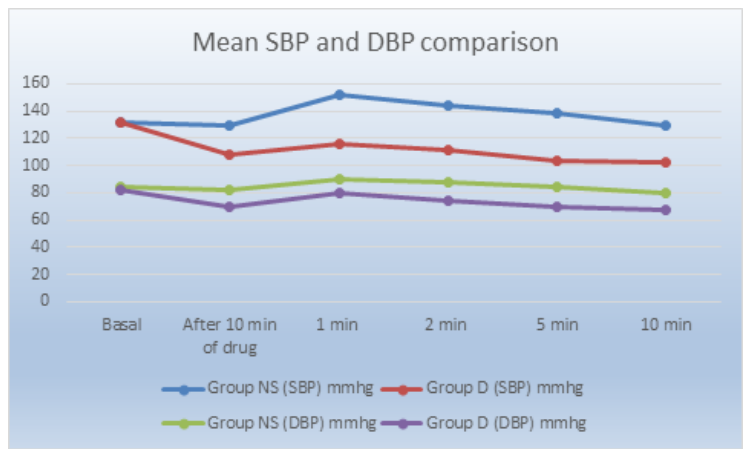

Figure 2: Mean Blood Pressure (systolic And Diastolic) Changes In Both Groups Compared To Baseline At Different Time Interval.

As shown in figure 1 \& 2, At 1 minute of laryngoscopy and intubation (T1), Increase in mean heart rate ( 40 beats/min in group NS vs 6 beats/min in group D), Change in mean systolic blood pressure (from $119.88 \pm 13.08$ to $154.94 \pm 8.64$ in group NS vs from $104.69 \pm 10.23$ to $114.35 \pm 14.22$ in group D) and rise in mean diastolic blood pressure (14 $\mathrm{mm} \mathrm{Hg}$ in group NS vs $9 \mathrm{~mm} \mathrm{Hg}$ in group D) from after induction value recorded. These changes are highly significant $(p<0.01)$.

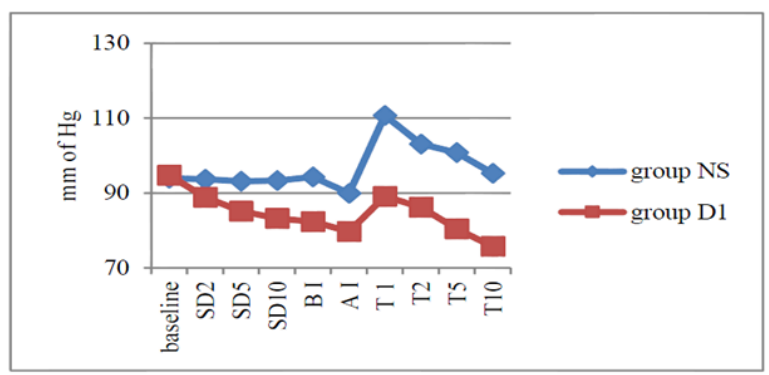

Figure 3: Mean arterial pressure changes.

\section{Figure 3: Mean Arterial Pressure Changes.}

As shown in Figure 1, 2 \& 3, Baseline mean heart rate, mean systolic and diastolic and mean arterial pressure were comparable in both the groups.

After 10 minutes of Inj. Dexmedetomidine administration Significant reduction in mean heart rate, systolic and diastolic blood pressure, mean arterial pressure observed in Group D but no changes seen in Group NS. $(\mathrm{P}<0.01)$.

Mean heart rate, mean blood pressure and mean arterial pressure were remain low after $1 \mathrm{~min}, 2 \mathrm{~min}, 5 \mathrm{~min}$ and $10 \mathrm{~min}$ (T1,T2, T5 and T10) of laryngoscopy and intubation when compared to baseline parameters in group Dl. Results were highly significant $(<0.01)$ compared to group NS.

\section{DISCUSSION}

Dexmedetomidine was used and compared for premedication alone or with other drugs to attenuate pressure response to laryngoscopy and intubation by various authors. They compared different doses of inj. Dexmedetomidine to study dose dependent efficacy. They conclude that intravenous Dexmedetomidine $1 \mu \mathrm{g} / \mathrm{kg}$ was more effective than $0.5 \mu \mathrm{g} / \mathrm{kg}$. while inj. Dexmedetomidine $0.3 \mu \mathrm{g} / \mathrm{kg}$ found very less effective to attenuate pressure response. It is seen that distribution halflife of i.v.Dexmedetomidine is approximately 6 minutes and onset of action is 10 to 15 minutes. So in present study we administered injection Dexmedetomidine $1 \mu \mathrm{g} / \mathrm{kg}$ diluted in 10 $\mathrm{ml}$ of normal saline and infused over 10 minutes intravenously. The 2 adrenoreceptors are involved in regulating the autonomic nervous system and cardiovascular system. 2 adrenoreceptor are located on blood vessels, where they mediate vasoconstriction as well as on sympathetic presynaptic terminals where they inhibit epinephrine and norepinephrine release. Effect of 2 agonists within locus ceruleus and their activation leads to sedation and hypnosis. A reduction of tonic levels of sympathetic outflow and an augmentation of vagal activity results in a decrease heart rate and cardiac output. We observed that mean heart rate, blood pressure and mean arterial pressure gradually but significantly reduced after 10 minutes of intravenous Dexmedetomidine administration. Our results are supported by previous studies.

In group D, we observed that hemodynamic parameters like heart rate, systolic and diastolic blood pressure and mean arterial pressure remain lower at all time intervals when compared to baseline value after intubation. 2 agonists produce hyperpolarization of noradrenergic neurons and suppression of neuronal firing in the locus ceruleus leads to 
decreased systemic noradrenalin release. The baroreceptor reflex is well preserved in patients who received Dexmedetomidine and reflex heart rate response to a pressure stimulus is augmented results in attenuation of sympathoadrenal responses and hemodynamic stability during laryngoscopy and tracheal intubation. Thus, we demonstrated that inj. Dexmedetomidine $1 \mu \mathrm{g} / \mathrm{kg}$ provide excellent and effective attenuation of hemodynamic changes occurred during laryngoscopy and intubation. Various authors had also considered injection Dexmedetomedine for attenuation and hemodynamic stability.

The anaesthetic and opioid sparing effect (due to a decrease in central noradrenergic transmission), sedative, hypnosis and analgesic properties of Dexmedetomidine reduce ancesthetic drugs, volatile agents requirements.

We did not observe any complication or side effects related to Dexmedetomidine infusion, laryngoscopy and intubation in present study.

\section{CONCLUSION}

Dexmedetomidine $1 \mu \mathrm{g} / \mathrm{kg}$ as premedication can be used safely and effectively to attenuate hemodynamic response to laryngoscopy and endotracheal intubation and also reduce requirement of induction agent in surgeries under general ancesthesia.

\section{REFERENCES:}

1. Steeds C, Harris L, Elder J, Dripps RD. Reflex circulatory responses to direct laryngoscopy and intubation under general anaesthesia. Anaesthesiology. $1951 \cdot 12(5): 556-66$.

2. Fox EJ, Sklar GS, Hill CH, VillanueVar, King BD. Complications related to the pressure response to endotracheal intubation. Anqesthesiology. 1977; 47(6):524-25.

3. Bruder N, Ortega D, Granthil C. Consequences and prevention methods of hemodynamic changes during laryngoscopy and intratracheal intubation. Ann FrÄnesthReanim. 1992;11(1):57-71.

4. Raval DL, Yadav VP. A comparative study of two different doses of Dexmedetomidine on haemodynamic response to induction of anesthesia and tracheal intubation. J ClinExp Res. 2014;2(3): 163-8.

5. Michael JS, Chang FL, Ho ST. Anaesthetic premedication: New horizons of an old practice. ActaAnesthesiologicaTaiwainica. 2014;52(3):134-142.

6. Khan FA, Ullah H. Pharmacological agents for preventing morbidity associated with the haemodynamic response to tracheal intubation. Cochrane Database Syst Rev. 2013;7:CD004087.

7. Ebert JP, Pearson D, Gelman S, Harris C. Circulatory response to laryngoscopy. The comparative effects of placebo, Fentanyl and Esmolol.Canadian J anaesthesia. 1989;36(3 pt. 1):301-6.

8. Gulabani M, Gurha P, Dass P, Kulshreshtha N. Comparative analysis of efficacy of lignocaine $1.5 \mathrm{mg} / \mathrm{kg}$ and two different doses of Dexmedetomidine $(0.5 \& 1 \mu \mathrm{g} / \mathrm{kg})$ in attenuating the hemodynamic pressure response to laryngoscopy and intubation. Anaesth essays Res. 2015;9(1):5-14.

9. Anju G. Dexmedetomidine: New avenues. J anaesthesiolClinPharmacol. 2011;27(3):297-302.

10. Arcangeli A, Alo DC, Gaspari R. Dexmedetomidine use in general anesthesia. Curr Drug Targets. 2009; 10(8):687-95.

11. Sagiroglu AE, Celik M, Orthon Z, S. Yuzer, B. Sen. Different doses of Dexmedetomidine on controlling haemodynamic response to tracheal intubation. Int J Anaesthesiol. 2010;27:2.

12. Smith KS, Shukla D, Sathesha M, Rao NS, Sudheesh K. Comparison of two different doses of dexmedetomidine in attenuating hemodynamic changes during laryngoscopy. J Evol Med Dent Sci. 2014;3:13501-8. 